\title{
Antitumor effects of the silencing of programmed cell death ligand 1 in colorectal cancer via immunoregulation
}

\author{
YILIN CHEN $^{1,2}$, YING HUANG ${ }^{1}$, XINGRONG LU $^{1}$, GAOXIONG WANG $^{2}$ and PAN CHI ${ }^{1}$ \\ ${ }^{1}$ Department of Colorectal Surgery, Fujian Medical University Union Hospital, Fuzhou, Fujian 350001; \\ ${ }^{2}$ Department of General Surgery, The Second Affiliated Hospital of Fujian Medical University, \\ Quanzhou, Fujian 362000, P.R. China
}

Received May 11, 2018; Accepted September 12, 2018

DOI: $10.3892 /$ or.2018.6738

\begin{abstract}
Activation of programmed cell death 1 (PD-1)/PD-ligand 1 (PD-L1) can promote immune suppression of the tumor microenvironment. However, the effects and mechanisms of PD-L1 silencing on colorectal cancer growth are largely unknown. In the present study, PD-L1 expression was compared in colorectal cancer and paracancerous tissues by immunofluorescence. A stable colorectal carcinoma cell line encoding PD-L1 short hairpin RNA (shRNA) was established. Thereafter, inoculated tumors were modeled in C57B/L6 mice. Experiments were divided into 3 groups: Control group, vector group, and PD-L1 silencing group (inoculated with the stable CT26 cell line encoding PD-L1 shRNA). Following decapitation of the mice, tumors were weighed and apoptosis of tumor cells was detected. The number and viability of cluster of differentiation (CD) $4^{+}$and $\mathrm{CD} 8^{+} \mathrm{T}$ cells were analyzed by flow cytometry and a cell counting kit assay, respectively. Compared with paracancerous tissue, colorectal cancer tissue extensively expressed PD-L1, RAC- $\alpha$ serine/threonine-protein kinase (AKT), and phosphatidylinositol 3-kinase (PI3K). Lymphocyte-activating gene 3 (LAG-3) expression was observed at the edge of tumor tissue, but rarely observed in paracancerous tissue. A stable CT26 cell line encoding PD-L1 shRNA was established, and lack of PD-L1 expression was confirmed by reverse transcription-polymerase chain reaction and western blotting. Compared with the control, the shPD-L1 group demonstrated reduced tumor growth, a high level of apoptosis in tumor cells, a low level of PI3K and AKT expression, and an increased number of cells and greater activity of $\mathrm{CD} 4^{+} \mathrm{T}$ and $\mathrm{CD} 8^{+} \mathrm{T}$ cells. Taken together, PD-L1 silencing promoted tumor cell apoptosis, at least in part, through the activation of $\mathrm{CD}^{+}$and $\mathrm{CD} 8^{+} \mathrm{T}$ cells.
\end{abstract}

Correspondence to: Professor Pan Chi, Department of Colorectal Surgery, Fujian Medical University Union Hospital, 29 Xinquan Road, Fuzhou, Fujian 350001, P.R. China

E-mail: chipan363@163.com

Key words: colorectal cancer, programmed cell death ligand 1, immunomodulation, apoptosis, lymphocyte-activating gene 3

\section{Introduction}

Colorectal cancer is one of the most common types of tumors of the digestive tract and can seriously threaten human health (1). Early detection, diagnosis, and treatment may improve the long-term quality of life of colorectal cancer patients. Considerable progress has been made in the field of early diagnosis, however comprehensive treatment, metastasis, and recurrence of cancer are still the most important factors that affect prognosis (2). Therefore, potential diagnostic markers and therapeutic targets are still urgently required.

Lymphocyte activating gene 3 (LAG-3) is a member of the immunoglobulin superfamily and has been shown to be a specific marker of $\mathrm{T}$ helper ( $\mathrm{TH}$ ) cells (3). As a negative costimulatory molecule, activation of LAG-3 can negatively regulate the function of lymphocytes and inhibit the function and life cycle of immune cells (4). Interestingly,LAG-3-positive tumor-infiltrating lymphocytes are thought to be an independent positive prognostic factor of non-small-cell lung cancer (5) and estrogen receptor-negative breast cancers (6). LAG-3 selectively increases cluster of differentiation (CD) 4 on the Treg surface, while LAG-3 antibody can reduce Treg activity in vivo. Inhibition or knockout of LAG-3 relieves the inhibitory effect of Treg on T cells. Programmed cell death 1 (PD-1)/ PD-ligand 1 (PD-L1) is another tumor checkpoint, and PD-1/ PD-L1 activation can promote immune suppression of the tumor microenvironment, causing tumor cells to escape from immune surveillance and destruction (7). Correspondingly, blocking the PD-1/PD-L1 signaling pathway can reverse the suppression of the tumor immune microenvironment and enhance anti-tumor activity of the endogenous immune system (8-10). PD-L1 binds to PD-1 on the surface of T cells to inhibit the destructive effect of $\mathrm{T}$ cells on tumor cells (11). Reducing PD-L1 plays an important role in promoting the tumor immune response and overcoming immune escape (12). However, the effects of PD-L1 silencing on the immune system in colorectal cancer have not been reported.

LAG-3-positive tumor-infiltrating lymphocytes are thought to be an independent positive prognostic factor for cancers (5), while PD-L1 plays an important role in promoting the tumor immune response (12). Based upon previous publications (13), the phosphatidylinositol 3-kinase $(\mathrm{PI} 3 \mathrm{~K}) / \mathrm{RAC}-\alpha$ serine/threonine-protein kinase (AKT) 
pathway is a cell survival pathway, supporting the development of tumors $(14,15)$. However, a link between PD-L1, LAG-3 and the PI3K/AKT pathway in colorectal cancer has not been established. In the present study, the expression levels of PD-L1, LAG-3, and the PI3K/AKT proteins of the signaling pathway were compared between colorectal cancer and paracancerous tissues. Thereafter, PD-L1 was silenced to investigate its effect on the tumor growth of colorectal cancer, and to assess the mechanisms involved. Importantly, LAG-3 activity was blocked using a specific LAG-3 antibody to verify the checkpoint of PD-L1 in colorectal cancer. The present study provides an experimental basis for the use of PD-L1 inhibition in treating colorectal cancer.

\section{Materials and methods}

Clinical samples. Ethical approval for the present study was obtained from the committee of Fujian Medical University Union Hospital (Fuzhou, China) and informed consent was obtained from the patients. Colorectal cancer and paracancerous tissues were collected from ten colorectal cancer patients (male/female: 7/3) who were diagnosed and received surgery treatment in the present hospital from October 2016 to December 2016. These patients had not received any chemotherapy or radiotherapy. Tissues were fixed in $4 \%$ paraformaldehyde for $24 \mathrm{~h}$ at $4^{\circ} \mathrm{C}$ for immunofluorescence and immunohistochemistry experiments.

Establishment of tumor models. A total of 21 female C57B/L6 (6-week-old, 20 $\pm 2 \mathrm{~g}$ ) mice were purchased from Hunan SLAC Experimental Animal Co. Ltd. (Shanghai, China; SCXK 2016-0002) and housed in a specific pathogen-free environment that was automatically maintained at a temperature of $23 \pm 2^{\circ} \mathrm{C}$, a relative humidity of $45-65 \%$, and with a controlled $12 \mathrm{~h}$ light/dark cycle. The animals had free to access food and water. All animal experiments were approved by the Ethics Committee of Fujian Medical University Union Hospital.

The C57B/L6 mice were randomly divided into 3 groups ( $n=7$ in each group): control, vector control group, and PD-L1 silenced with short hairpin RNA (shPD-L1) group. CT26 cells were purchased from the Shanghai Cell Bank of Chinese Academy of Science (Shanghai, China) and cultured in Dulbecco's Modified Eagle's Medium (DMEM; Thermo Fisher, Scientific, Inc., Waltham, MA, USA) supplemented with $10 \%$ fetal bovine serum (FBS; Hyclone; GE Healthcare Life Sciences, Logan, UT, USA) at $37^{\circ} \mathrm{C}$ in an environment containing $5 \% \mathrm{CO}_{2}$. Cells at $70 \%$ confluence were transfected with empty vector $(1 \mu \mathrm{g})$ or PD-L1 shRNA $(1 \mu \mathrm{g})$ (both were obtained from Santa Cruz Biotechnology, Inc., Dallas, TX, USA) using Lipofectamine ${ }^{\circledR} 2000$ (Invitrogen; Thermo Fisher Scientific, Inc.). A total of $24 \mathrm{~h}$ after transfection, the cells were used in the following injection. In the control group, CT26 cells in the logarithmic growth phase $\left(1 \times 10^{7}\right)$ were diluted in $0.2 \mathrm{ml}$ PBS and administered through subcutaneous injection into the C57B/L6 mice. In the vector control group, CT26 cells transfected with control vector were diluted in $0.2 \mathrm{ml} \mathrm{PBS}$ and injected into the C57B/L6 mice. In the PD-L1 silenced group, CT26 cells transfected with viral PD-L1 shRNA were diluted in $0.2 \mathrm{ml}$ PBS and injected into the C57B/L6 mice.
General conditions of the mice were monitored daily and the tumor size was measured every 2 days. At 7 days after injection of tumor cells, LAG-3 antibody (cat. no. ab213524; Abcam, Cambridge, MA, USA) was injected every 3 days via intraperitoneal injection $(10 \mathrm{mg} / \mathrm{kg})$. At the 14 th day after tumor cell injection, mice were decapitated following anesthesia (5\% isoflurane), and whole tumors were removed. Tumor specimens were fixed in $4 \%$ paraformaldehyde $(\mathrm{pH} 7.4)$ at $4^{\circ} \mathrm{C}$ overnight and then embedded in paraffin for tissue sectioning.

Immunohistochemistry. Tumor tissues and paracancerous tissues were fixed in $4 \%$ paraformaldehyde for $\sim 1$ week at $4^{\circ} \mathrm{C}$. Tissues were then dehydrated, embedded, and sliced $(2 \mu \mathrm{m})$. Thereafter, paraffin sections were dewaxed and hydrated in $70,75,80,85$ and $95 \%$ alcohol. Staining was performed using monoclonal antibodies against PD-L1 (1:100; cat. no. ab199380; Abcam), LAG-3 (1:100; cat. no. bs-2646R; BIOSS, Beijing, China), AKT (1:100; cat. no. bs-0115R; BIOSS), and PI3K (1:100; cat. no. ab191606; Abcam). Endogenous peroxidase activity was blocked with $3 \%(\mathrm{v} / \mathrm{v}) \mathrm{H}_{2} \mathrm{O}_{2}$ for $5 \mathrm{~min}$ at room temperature. Subsequently, slides were incubated with primary antibodies overnight at $4^{\circ} \mathrm{C}$, followed by incubation with horseradish peroxidase-labeled goat anti-rabbit IgG secondary antibody (1:10,000; cat. no. A16104SAMPLE; Thermo Fisher Scientific, Inc.), Alexa Fluor 593 goat anti-mouse IgG (1:100; cat. no. CW0159S; CW Biotech, Beijing, China), or Alexa Fluor 488 goat anti-rabbit IgG (1:100; cat. no. CW0114S; CWBIO, Beijing, China) for $30 \mathrm{~min}$ at room temperature. The fluorescence intensity was analyzed by ImageProPlus software 6.0 (National Institutes of Health, Bethesda, MD, USA). Immunohistochemical staining was visualized with 3,3'-diaminobenzidine chromogen for $3 \mathrm{~min}$ at room temperature. The nucleus was counterstained by hematoxylin at room temperature for $3 \mathrm{~min}$. Both images obtained from immunohistochemistry and immunofluorescence were obtained using a microscope (CX41; Olympus Corporation, Tokyo, Japan). The grey density was calculated by ImageProPlus software.

Hematoxylin and eosin $(H \& E)$ staining. Tissues were rinsed and then dehydrated, embedded, and sliced. Paraffin sections were dewaxed and hydrated. Sections were stained with hematoxylin solution for $5 \mathrm{~min}$ and with eosin for $3 \mathrm{~min}$ at room temperature. Images were obtained using light microscopy.

Terminal deoxynucleotidyl transferase (TdT)-mediated dUTP nick end labeling (TUNEL) assay. A TUNEL assay was carried out in the paraffin-embedded tissues. Samples were sectioned into $2-\mu \mathrm{m}$ slices, dewaxed in ethanol (75, 80,95 and $100 \%$ ), and washed with PBS (3 times for 5 min each). Fresh proteinase $\mathrm{K}$ was prepared $(2 \mu \mathrm{l}$ proteinase $\mathrm{K}$ in $98 \mu \mathrm{l} \mathrm{PBS})$ and applied to cover the tissues $(100 \mu \mathrm{l})$ at $37^{\circ} \mathrm{C}$ for $30 \mathrm{~min}$. Finally, TdT $(2 \mu \mathrm{l})$ and fluorescent reagent $(48 \mu \mathrm{l})$ were mixed and applied to stain the tissue at $37^{\circ} \mathrm{C}$ for $60 \mathrm{~min}$ (cat. no. C1088; Beyotime Institute of Biotechnology, Haimen, China). After washing, slides were covered with anti-fading reagent and observed at least five fields under a fluorescence microscope.

Flow cytometry. Tumor tissues were ground and passed through a 200-mesh. Following centrifugation $\left(4^{\circ} \mathrm{C}, 400 \mathrm{x}\right.$ g, $\left.3 \mathrm{~min}\right)$, cells 
Table I. Primer sequences for the target genes.

\begin{tabular}{clccc}
\hline Genes & \multicolumn{1}{c}{ Primer sequences $\left(5^{\prime}-3^{\prime}\right)$} & Primer length $(\mathrm{bp})$ & Product length $(\mathrm{bp})$ & Annealing temperature $\left({ }^{\circ} \mathrm{C}\right)$ \\
\hline PD-L1 & & 24 & 111 & 57 \\
F & CCATCTTATTATGCCTTGGTGTAG & 25 & & \\
R & TTTGCTTCTTTGAGTTTGTATCTTG & 140 & 54 \\
PI3K & & 18 & & 58.7 \\
F & CCAACACCTTCATCATCC & 18 & 231 & \\
R & CTCCTCCTCCTGCTTCTT & & & 58.6 \\
AKT & & 21 & 100 & \\
F & TGTGATCTTAATGTGCCCGTC & 21 & & \\
R & TACTCTTTCCAGACCCACGAC & & & \\
GAPDH & & 20 & & \\
F & GAAGGTCGGAGTCAACGGAT & 19 & & \\
R & CCTGGAAGATGGTGATGGG &
\end{tabular}

PD-L1, programmed cell death ligand 1; AKT1, RAC- $\alpha$ serine/threonine-protein kinase 1; PI3K, phosphatidylinositol 3-kinase; F, forward; $\mathrm{R}$, reverse.
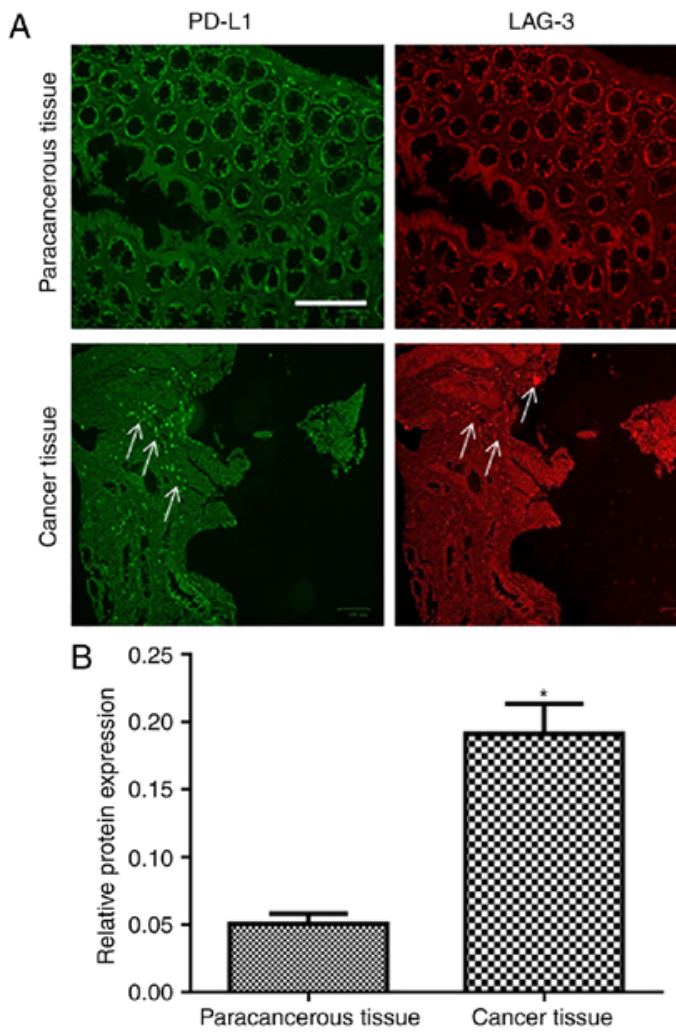
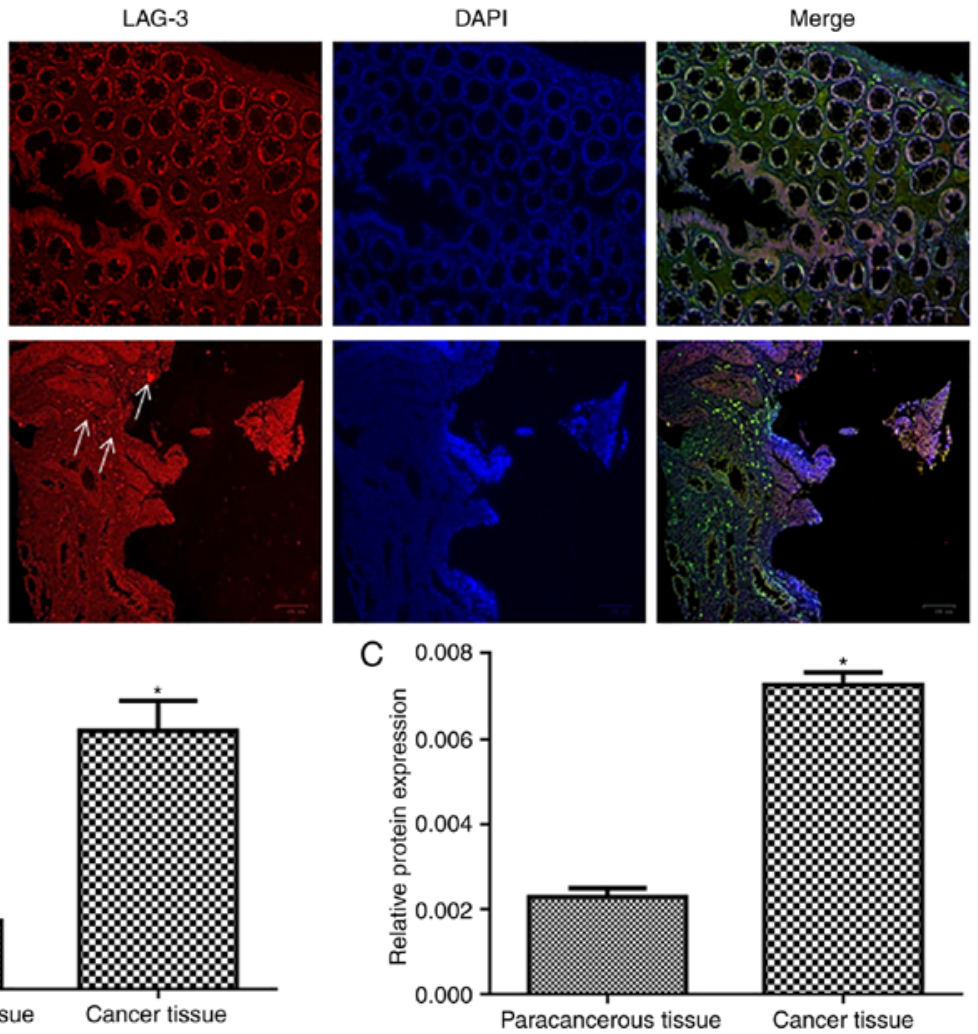

Figure 1. PD-L1 expression is increased in cancer tissue. (A) Representative images of PD-L1 and LAG-3 expression. Green color represents PD-L1 expression, while red color represents LAG-3 expression. Scale bar, $100 \mu \mathrm{m}$. Arrows indicate the positive staining. (B) Quantification data of PD-L1 expression showing that PD-L1 expression in the carcinoma tissue was significantly increased compared with paracancerous tissue. (C) Quantification data of LAG-3 expression showing that LAG-3 expression in the carcinoma tissue was significantly increased compared with paracancerous tissue. ${ }^{*} \mathrm{P}<0.05$ vs. paracancerous tissue. (Paired Student's t-test). PD-L1, programmed cell death ligand 1; LAG3, lymphocyte-activating gene 3.

were collected. Antibodies against CD4-fluorescein isothiocyanate (1:400; cat. no. 561833; BD Biosciences, Franklin Lakes, NJ, USA) and CD8-phycoerythrin (1:400; cat. no. 561949; BD Biosciences) were added to each tube. After incubation at room temperature for $10 \mathrm{~min}$ in the dark, cells were detected by flow cytometer (NovoCyte 2060R; ACEA Biosciences, Inc., Hangzhou, China) and data were analyzed by FlowJo 10 (FlowJo, LLC., Portland, OR, USA). 
A


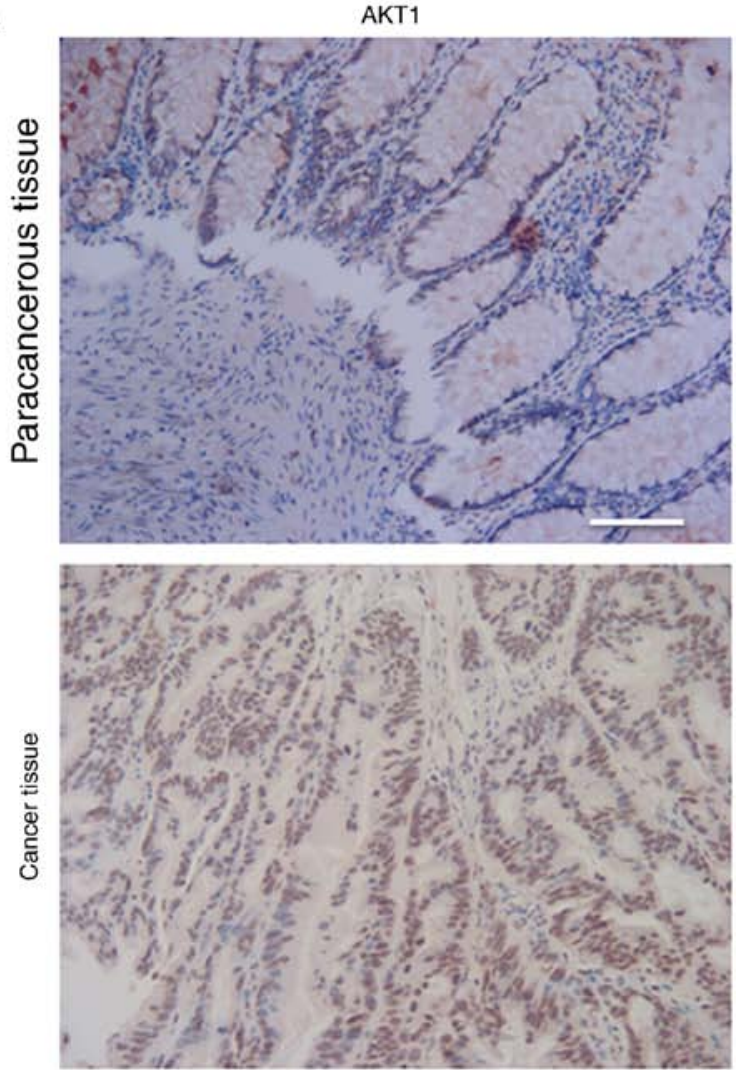

PI3K
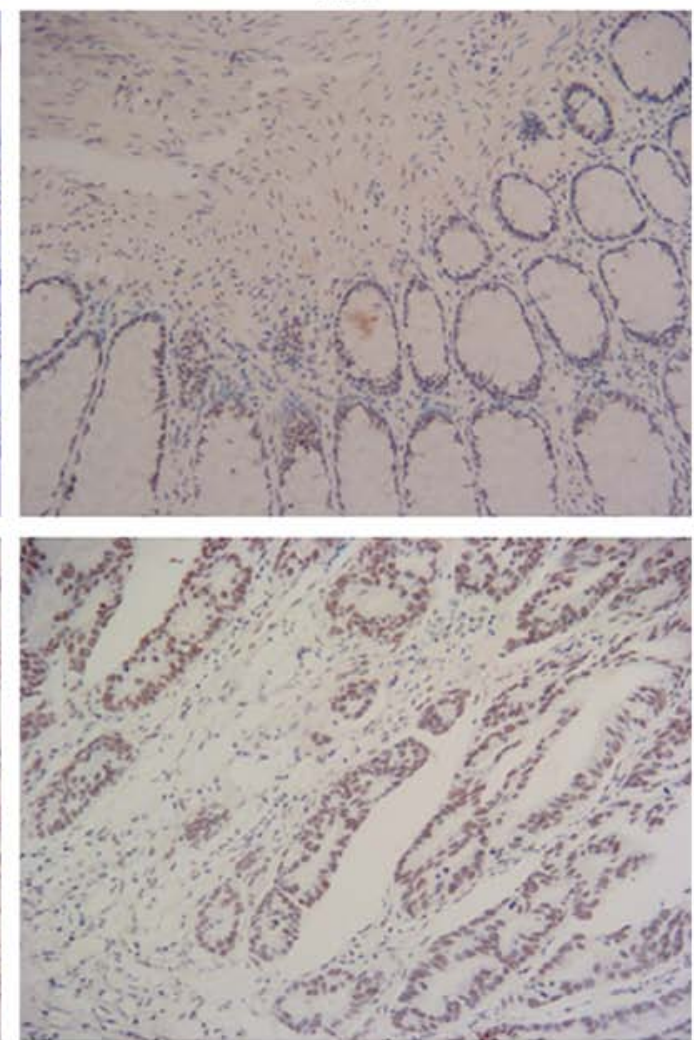

B Tissue adjacent to carcinoma

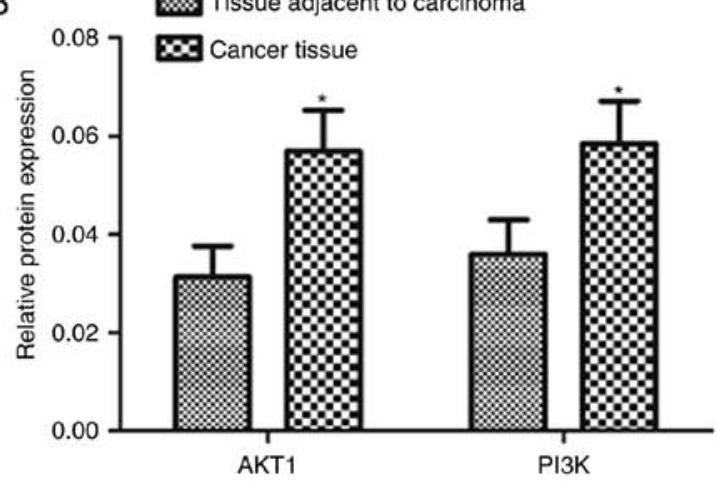

Figure 2. AKT1 and PI3K expression is increased in cancer tissue.(A) Representative images of AKT1 and PI3K expression. Scale bar, $100 \mu \mathrm{m}$.(B) Quantification data of AKT and PI3K expression showing that AKT and PI3K expression in carcinoma tissues was significantly increased compared with paracancerous tissue. "P<0.05 vs. paracancerous tissue. (Paired Student's t-test). AKT1, RAC- $\alpha$ serine/threonine-protein kinase 1; PI3K, phosphatidylinositol 3-kinase.

Cell Counting Kit (CCK)-8 assay. The $\mathrm{CD}^{+}$and $\mathrm{CD} 8^{+}$ $\mathrm{T}$ cells in the tumor tissues were sorted using a flow sorting apparatus, and then placed on a 96-well plate and cultured for 24 h. $10 \mu \mathrm{l} \mathrm{CCK-8} \mathrm{(Gibco;} \mathrm{Thermo} \mathrm{Fisher} \mathrm{Scientific,} \mathrm{Inc.)}$ was added to each well. After an additional incubation for $4 \mathrm{~h}$ in a $\mathrm{CO}_{2}$ incubator at $37^{\circ} \mathrm{C}$, the absorbance was detected by a microplate reader (Thermo Fisher Scientific, Inc.) at a wavelength of $490 \mathrm{~nm}$. Cell viability was defined by optical density (OD) values.

Reverse transcription-polymerase chain reaction (RT-PCR). Following the various treatments, total RNA was extracted using TRIzol ${ }^{\circledR}$ (Thermo Fisher Scientific, Inc.) according to the manufacturer's protocol. mRNA purity was confirmed by OD280/OD260 using a spectrophotometer and amplified by a one-step RT-PCR kit (cat. no. DRR046A; Takara Bio, Inc.,
Otsu, Japan). The primers were added into a $25-\mu 1$ PCR reaction system following a protocol of $94^{\circ} \mathrm{C}$ denaturation $45 \mathrm{sec}$, $56^{\circ} \mathrm{C}$ annealing $45 \mathrm{sec}$, and $72^{\circ} \mathrm{C}$ extension $60 \mathrm{sec}$ for 40 cycles. Primers are listed in Table I.

Western blotting. Following treatments, protein was extracted using a protein isolation kit (cat. no. 28-9425-44, ReadyPrep; GE Healthcare Life Sciences) (containing phenylmethane sulfonyl fluoride), as previously described (16). Protein samples were heated at $100^{\circ} \mathrm{C}$ for $10 \mathrm{~min}$, and the protein concentration was quantified using a bicinchoninic acid assay kit (Beyotime Institute of Biotechnology). Proteins ( $25 \mu \mathrm{g} / \mathrm{well})$ were separated by SDS-PAGE (12\% gel), and protein was then transferred onto a nitrocellulose membrane. Membrane was blocked with 5\% nonfat milk in phosphate-buffered saline with Tween-20 at room temperature for $2 \mathrm{~h}$. Primary 
antibodies against, PD-L1 (1:1,000; cat. no. ab199380; Abcam), AKT (1:1,000; cat. no. bs-0115R; BIOSS), PI3K (1:1,000; cat. no. ab191606; Abcam) and GAPDH (1:1,000; cat. no. ab24071; Abcam) were incubated with membranes overnight at $4^{\circ} \mathrm{C}$. After washing ( 3 times for $10 \mathrm{~min}$ each), membranes were incubated with the goat Anti-Rabbit IgG H\&L (HRP) (1:10,000; cat. no. ab131368; Abcam) for $2 \mathrm{~h}$ at room temperature. Chemiluminescent substrate detection reagent (cat. no. RPN2133; GE Healthcare Life Sciences) was applied to reveal the signals. Target bands were analyzed by ImageJ software for grayscale analysis.

Statistical analysis. Data were expressed as mean and standard deviation ( $\mathrm{n}=7$ in each group) and analyzed using SPSS software, version 19.0 (IBM SPSS, Armonk, NY, USA). Statistical significance was assessed using a paired Student's t-test (parametric) or one-way analysis of variance with Newman-Keuls as the post hoc test. $\mathrm{P}<0.05$ was considered to indicate a statistically significant difference.

\section{Results}

Expression of $P D-L 1$ and $L A G-3$ is increased in cancerous tissue compared with paracancerous tissue. PD-L1 expression was extensively observed in cancer tissues (Fig. 1A). LAG-3 expression was observed at the edge of tumors. Conversely, very little PD-L1 expression was observed in paracancerous tissues. LAG-3 expression was not observed in paracancerous tissues. Quantitative results demonstrated that the expression of PD-L1 and LAG-3 in the carcinoma tissue was significantly increased compared with in the paracancerous tissue $(\mathrm{P}<0.05$; Fig. $1 \mathrm{~B}$ and $\mathrm{C})$.

Expression of PI3K and AKT is increased in cancer tissue compared with paracancerous tissue. The present study detected the expression levels of AKT and PI3K in carcinoma tissue. Expression of AKT and PI3K was extensively observed in cancer tissues, but rarely observed in paracancerous tissue (Fig. 2A). Quantitative results showed that the expression of AKT and PI3K in carcinoma tissues was significantly increased compared with paracancerous tissue ( $\mathrm{P}<0.05$; Fig. 2B).

$P D-L 1$ silencing reduces tumor growth. Based upon the aforementioned results, the present study designed experiments to inhibit PD-L1 by shRNA. In addition, to avoid the effect of LAG-3, its activity was blocked by using an LAG-3 antibody in all the groups. PD-L1 expression was significantly reduced following transfection with shRNA PD-L1 $(\mathrm{P}<0.05$; Fig. 3). The established cell lines were injected into C57B/L6 mice, and tumor growth was evaluated. PD-L1 and LAG-3 expression was also detected in tumor tissues (Fig. 4A). PD-L1 expression was significantly reduced in the PD-L1 silenced group, compared with the control group $(\mathrm{P}<0.05$; Fig. 4B), whereas LAG-3 expression in the 3 groups was comparable (Fig. 4C).

Tumors weighed less in the PD-L1 silenced group, compared with the control group $(\mathrm{P}<0.05 ;$ Fig. $5 \mathrm{~A}$ and $\mathrm{B})$. Tumor growth was significantly inhibited in the PD-L1 silenced group, compared with the control group $(\mathrm{P}<0.05$; Fig. $5 \mathrm{C})$.
A
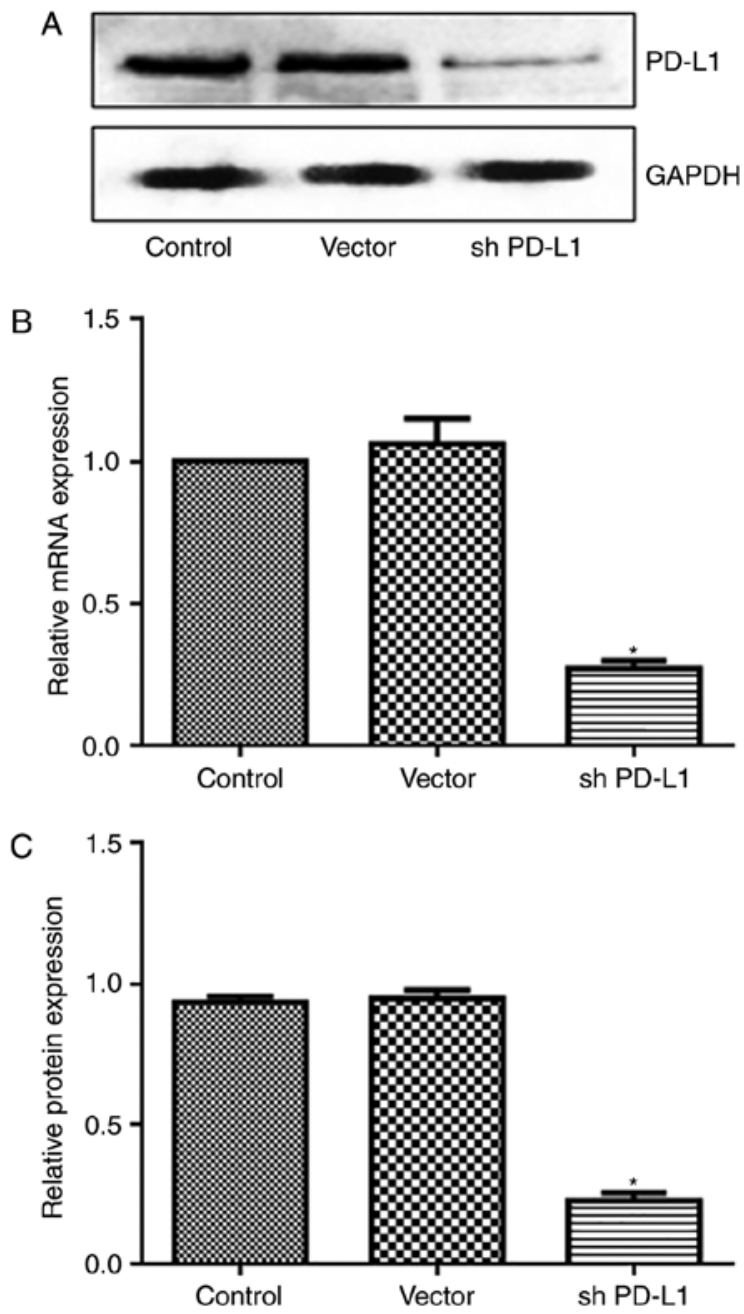

Figure 3. PD-L1 expression is reduced in CT26 cells by lenti-viral expression of PD-L1 shRNA. (A) Representative blot of PD-L1 protein expression levels. (B) mRNA expression of PD-L1 was significantly reduced after transfection with shRNA PD-L1. (C) Protein expression of PD-L1 was significantly reduced after transfection with shRNA PD-L1. ${ }^{*} \mathrm{P}<0.05$ vs. control. (One-way analysis of variance with Newman-Keuls). Sh, short hairpin; PD-L1, programmed cell death ligand 1 .

Tumor cells in the PD-L1 silenced group had a loose arrangement and were inactive in cell growth (Fig. 6). In control groups, tumor cells were tightly arranged, and the size was relatively uniform.

The present study also detected the apoptosis of tumor cells. Apoptosis was increased in the shPD-L1 group compared with control groups $(\mathrm{P}<0.05$; Fig. 7$)$.

$P D$-L1 silencing promotes $C D 8^{+}$and $C D 4^{+} T$ cells in tumor tissue. Flow cytometry was used to detect the expression of $\mathrm{CD}^{+}$and $\mathrm{CD}^{+}{ }^{+} \mathrm{T}$ cells in tumor tissue. Results showed that PD-L1 silencing increased the number of CD4 ${ }^{+}$ $\mathrm{T}$ cells and $\mathrm{CD} 8^{+} \mathrm{T}$ cells in the tumor, compared with controls ( $\mathrm{P}<0.05$; Fig. 8).

The CCK-8 assay also showed that cell viability of $\mathrm{CD} 8^{+}$ and $\mathrm{CD} 4^{+} \mathrm{T}$ cells was significantly increased in the PD-L1 silenced group compared with controls $(\mathrm{P}<0.05$; Fig. 9).

$P D-L 1$ silencing reduced PISK and AKT expression in tumor tissue. Expression of PD-L1, PI3K, and AKT in 
A
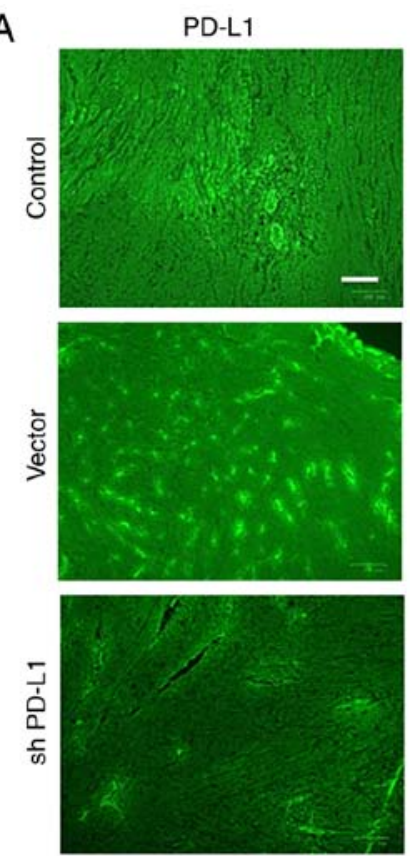

B

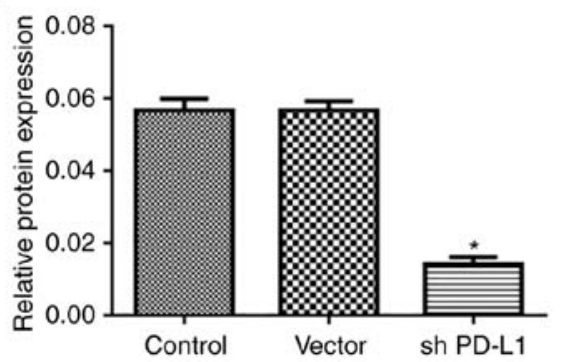

LAG-3
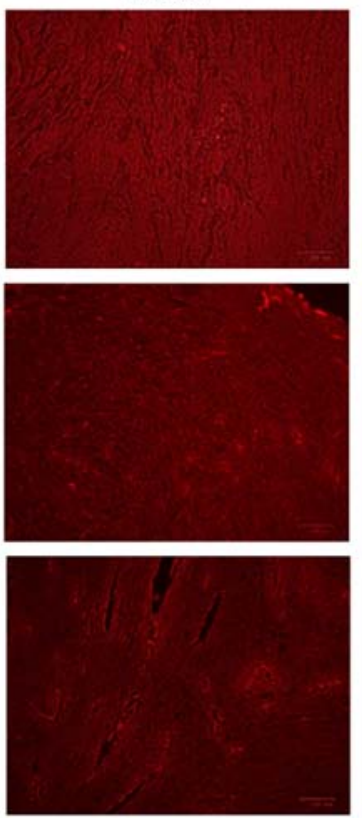

C

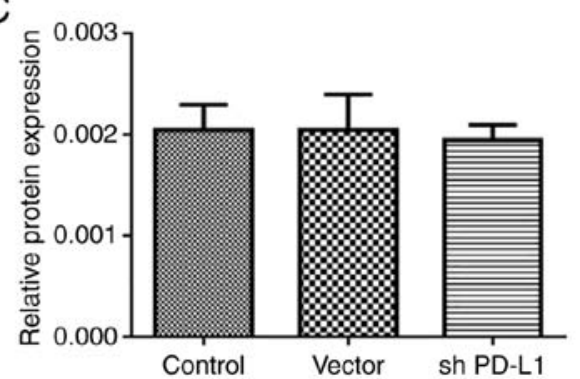

Figure 4.PD-L1 expression is reduced in the inoculated tumors. (A) Representative images of PD-L1 and LAG-3 expression. Scale bar, $100 \mu \mathrm{m}$. (B) Quantification data of PD-L1 expression showing that PD-L1 expression was significantly reduced after transfection with shRNA PD-L1. (C) Quantification data of LAG-3 expression showing that LAG-3 expression was comparable in each group. " $\mathrm{P}<0.05$ vs. control. (One-way analysis of variance with Newman-Keuls). PD-L1, programmed cell death ligand 1; LAG3, lymphocyte-activating gene 3.

A

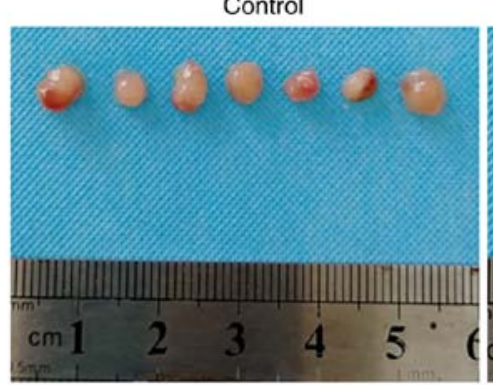

B

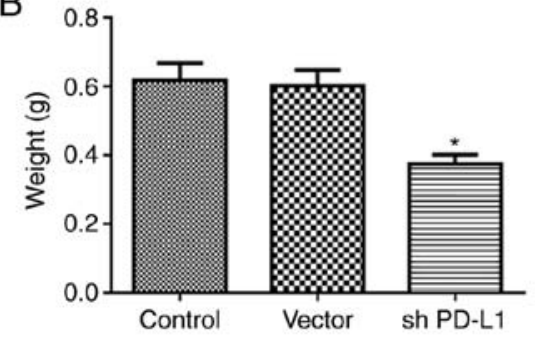

Vector

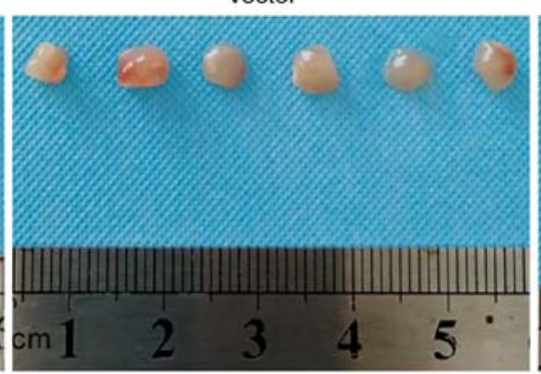

sh PD-L1
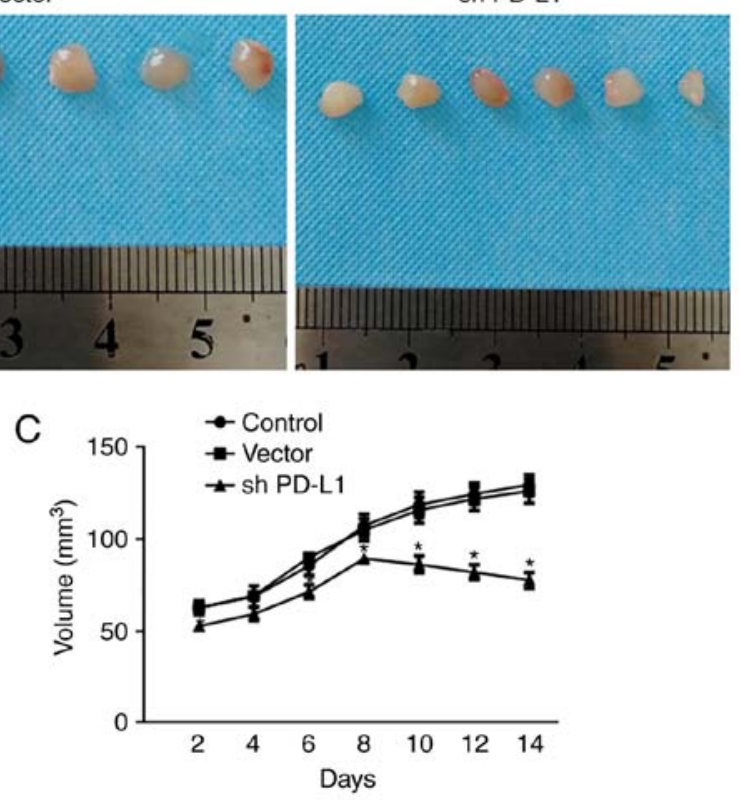

Figure 5. PD-L1 silencing reduces tumor growth. (A) Representative images of tumors obtained at the 14th day after tumor cell inoculation. (B) Tumors weighed less in the PD-L1 silenced group compared with the control group. (C) Tumor growth was significantly inhibited in the PD-L1 silenced group as evidenced by the tumor volume. ${ }^{*} \mathrm{P}<0.05$ vs. control. (One-way analysis of variance with Newman-Keuls). Sh, short hairpin; PD-L1, programmed cell death ligand 1 . 

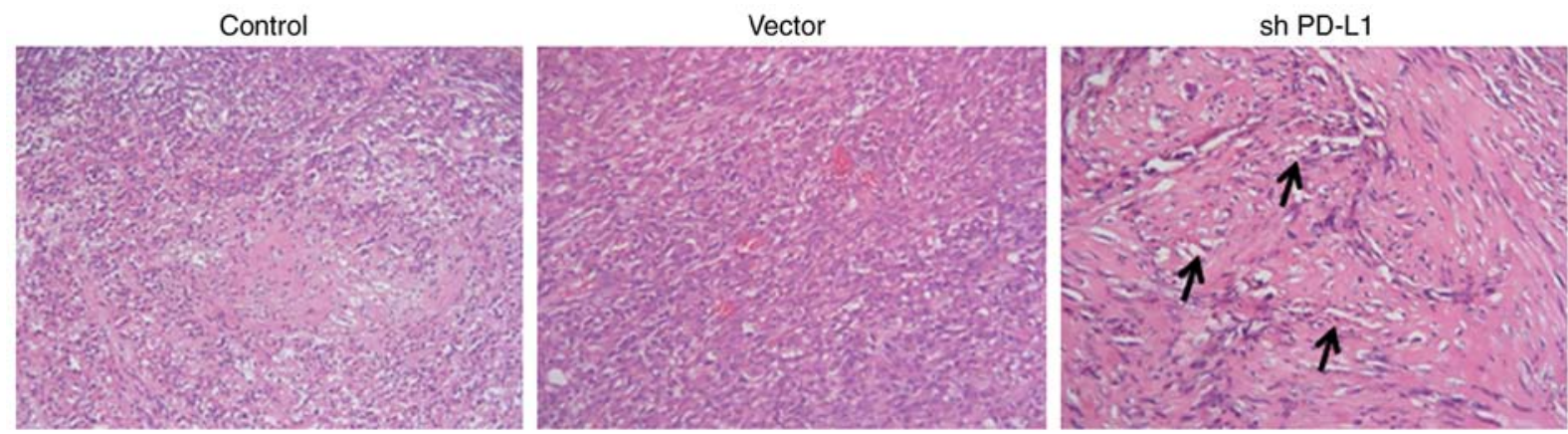

Figure 6. Hematoxylin and eosin staining. Tumor cells in the shPD-L1 group were loosely arranged and inactive in cell growth (shown by arrows). In control groups, tumor cells were tightly arranged, and the size was relatively uniform. Magnification, x200. Sh, short hairpin; PD-L1, programmed cell death ligand 1.
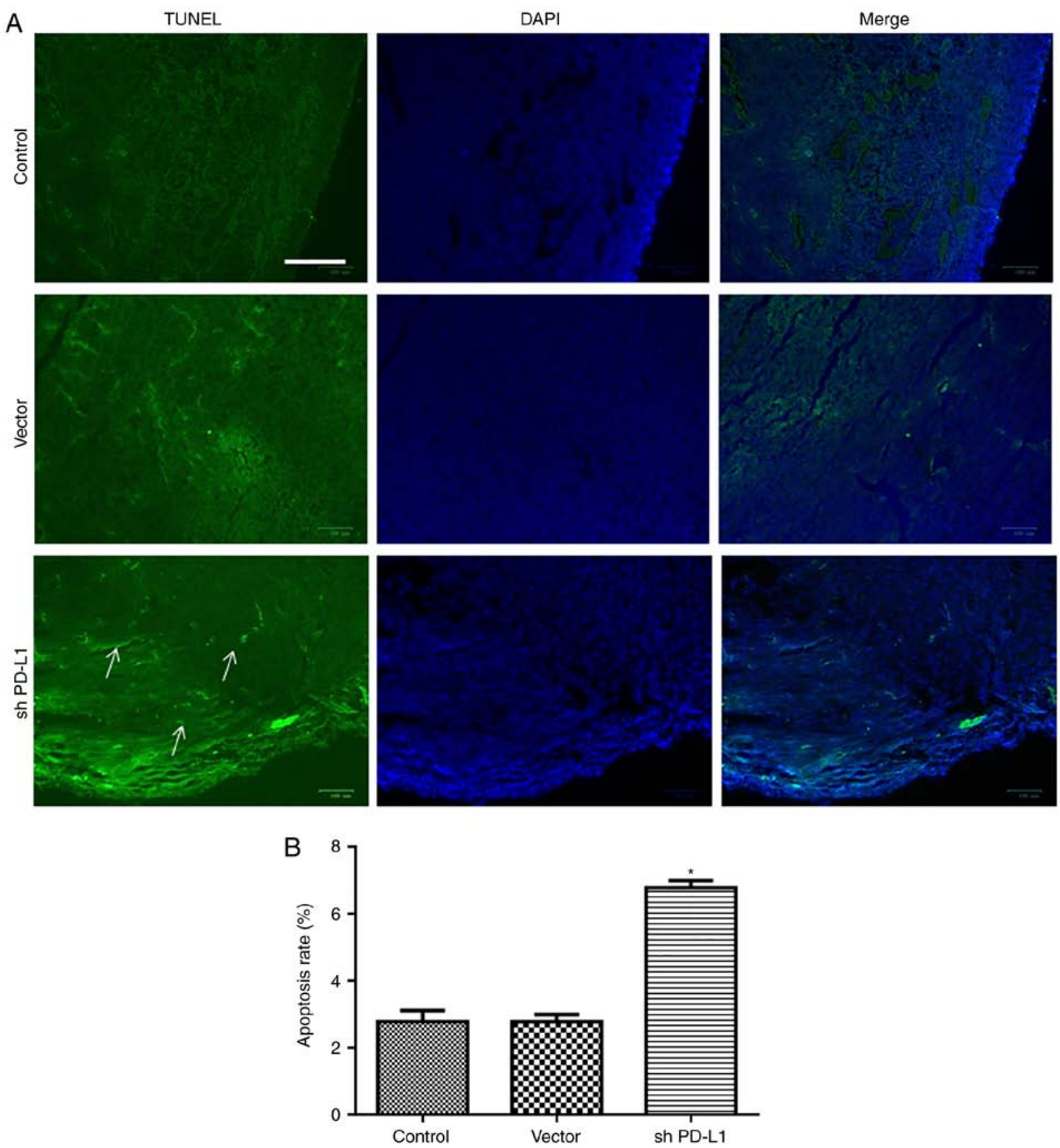

Figure 7. PD-L1 silencing promotes tumor cell apoptosis. (A) Representative images of TUNEL assay; (B) Quantification data showing that increased apoptosis was observed in the sh-PD-L1 group compared with control group. Scale bar, $100 \mu \mathrm{m}$. "P<0.05 vs. control. (One-way analysis of variance with Newman-Keuls). Sh, short hairpin; PD-L1, programmed cell death ligand 1; TUNEL, Terminal deoxynucleotidyl transferase (TdT)-mediated dUTP nick end labeling. 

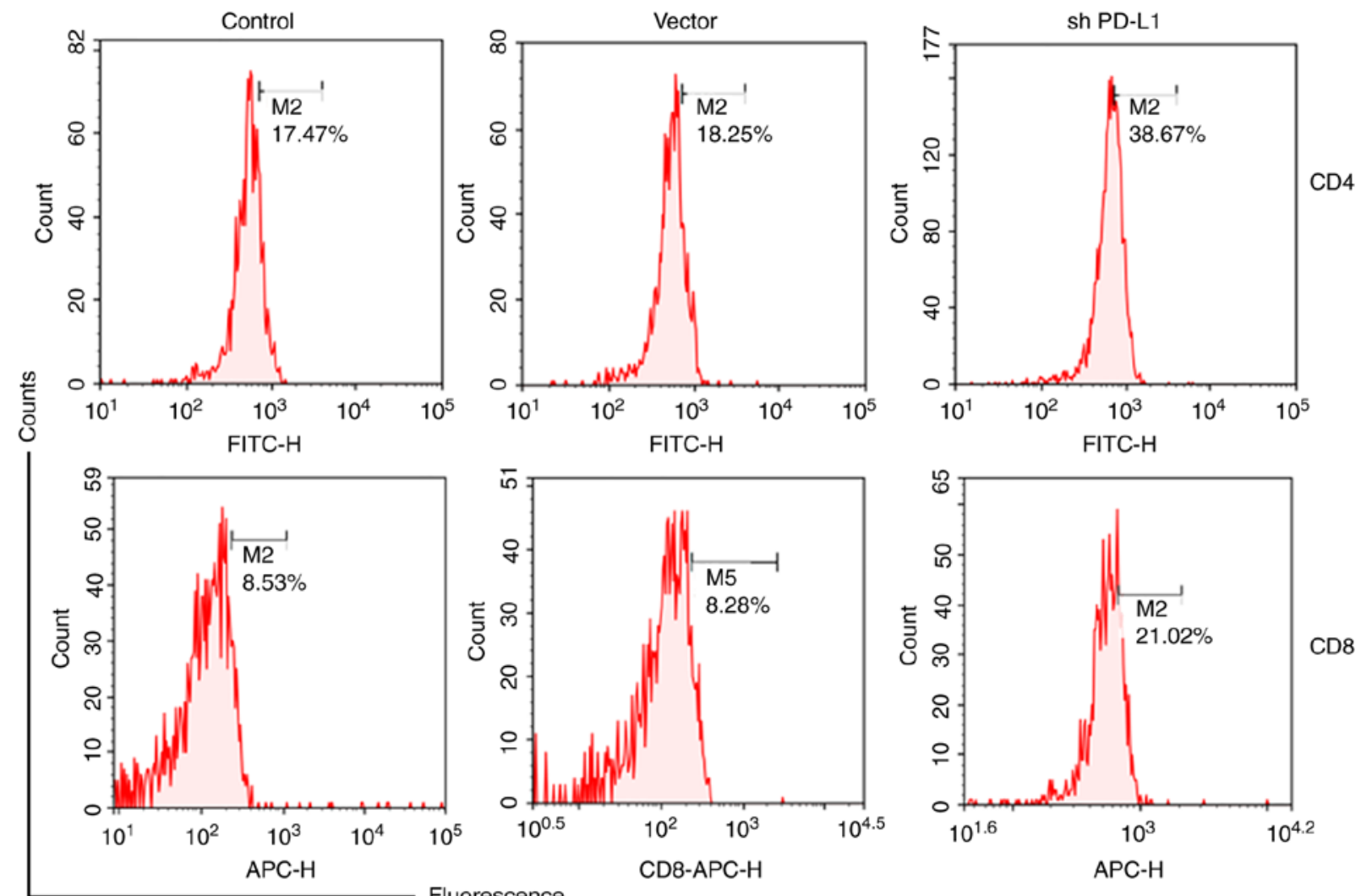

Fluorescence

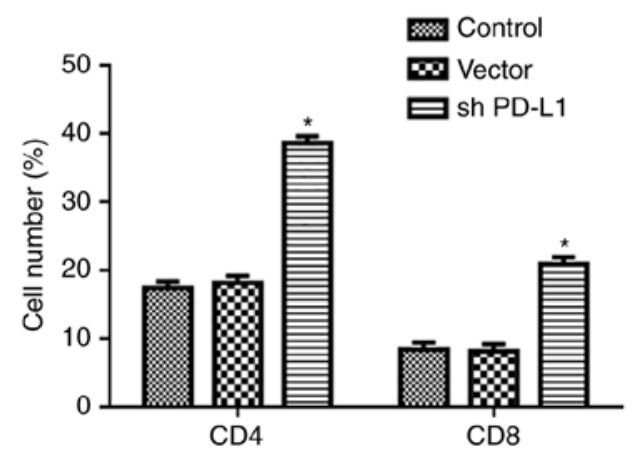

Figure 8. PD-L1 silencing increases the numbers of $\mathrm{CD}^{+}$and $\mathrm{CD} 4^{+} \mathrm{T}$ cells. Upper panel: Representative images of flow cytometry; lower panel: Quantification data showing that PD-L1 silencing increased the numbers of $\mathrm{CD} 4^{+} \mathrm{T}$ cells and $\mathrm{CD} 8^{+} \mathrm{T}$ cells in the tumors, compared with controls. ${ }^{*} \mathrm{P}<0.05$ vs. control. (One-way analysis of variance with Newman-Keuls). Sh, short hairpin; PD-L1, programmed cell death ligand 1; CD, cluster of differentiation.
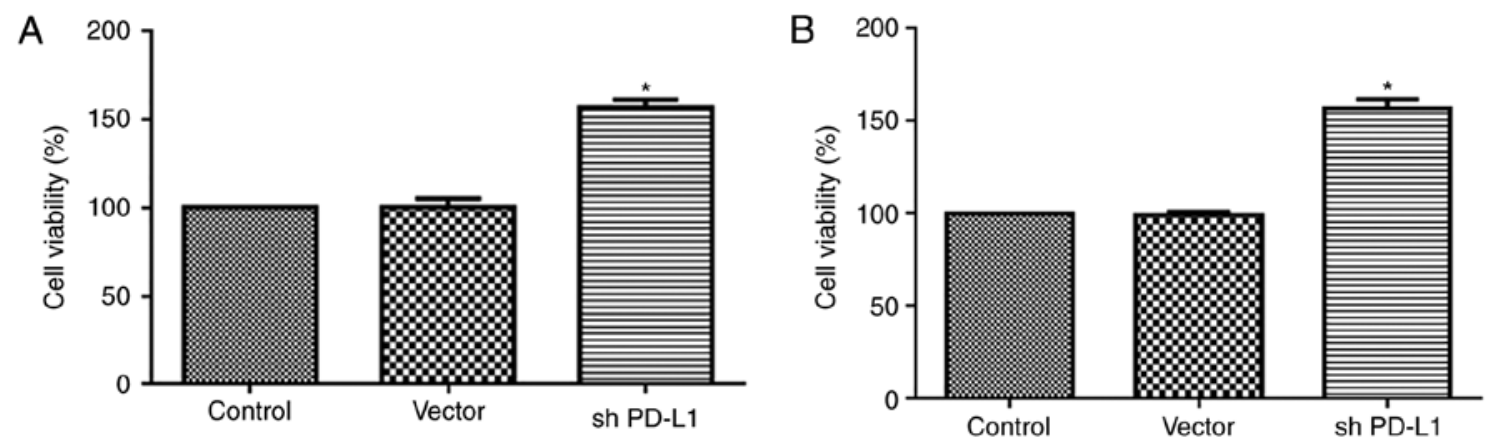

Figure 9. PD-L1 silencing promotes cell activity of $\mathrm{CD} 8^{+}$and $\mathrm{CD} 4^{+} \mathrm{T}$ cells. (A) $\mathrm{CD} 4^{+} \mathrm{T}$ cells. (B) $\mathrm{CD} 8^{+} \mathrm{T}$ cells. ${ }^{*} \mathrm{P}<0.05$ vs. control. Sh, short hairpin; PD-L1, programmed cell death ligand $1 ; \mathrm{CD}$, cluster of differentiation.

tumor tissues of each group is shown in Fig. 10. Compared with the control group, the expression of PD-L1, PI3K, and AKT in the PD-L1 silenced group was significantly decreased $(\mathrm{P}<0.05)$. 


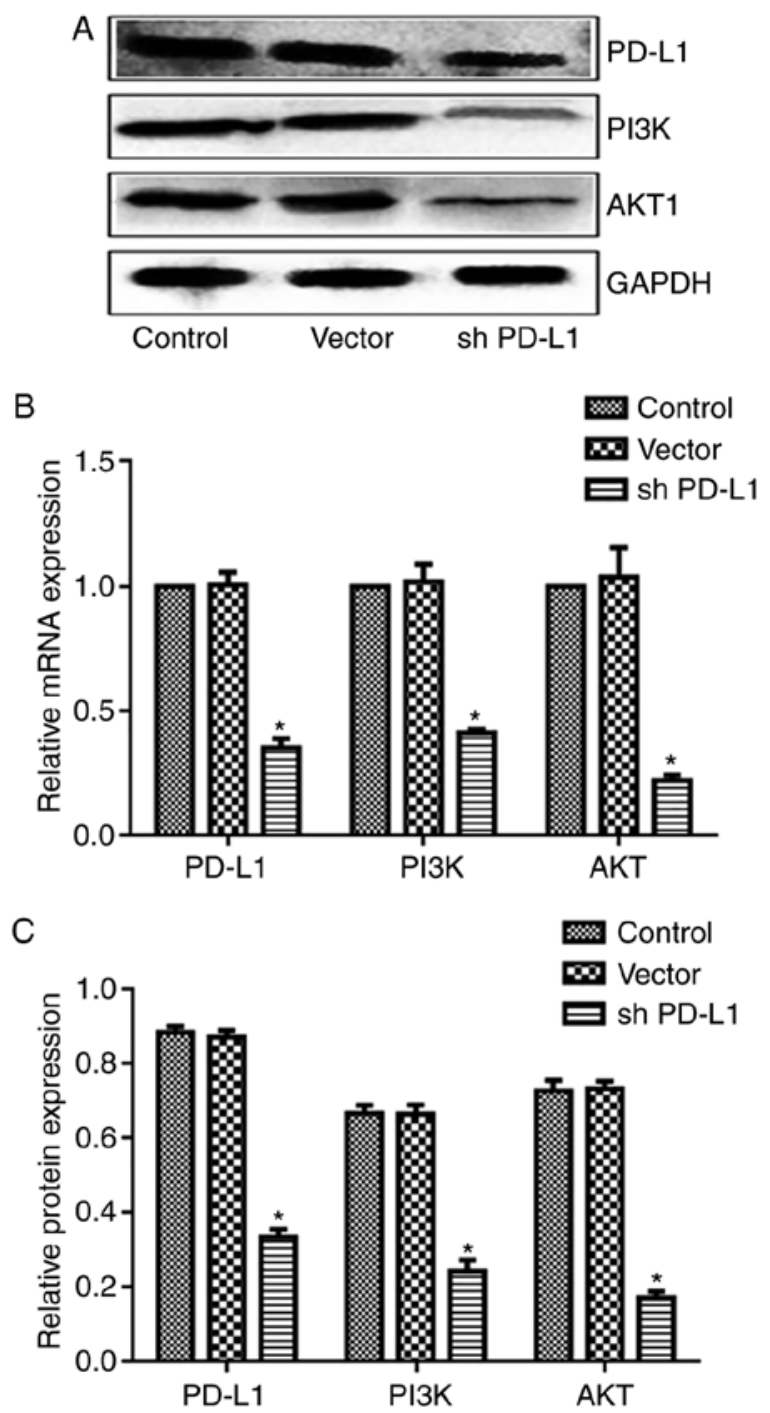

Figure 10. PD-L1 silencing reduces PI3K and AKT expression in tumor cells. (A) Representative blots of PD-L1, PI3K, and AKT. (B) mRNA expression of PD-L1, PI3K, and AKT. (C) Protein level of PD-L1, PI3K, and AKT showing that expression of PD-L1, PI3K, and AKT in the PD-L1 silenced group decreased. ${ }^{*} \mathrm{P}<0.05$ vs. control. (One-way analysis of variance with Newman-Keuls). Sh, short hairpin; PD-L1, programmed cell death ligand 1; AKT1, RAC- $\alpha$ serine/threonine-protein kinase 1; PI3K, phosphatidylinositol 3-kinase.

\section{Discussion}

Colorectal cancer seriously threatens human health, although great progress has been made in its treatment. Metastasis and recurrence of colorectal cancer are still the primary causes of poor prognosis. As reported, colorectal cancer is an evolutionary process involving multiple genes and multi-stages, particularly oncogene activation and tumor suppressor gene inactivation (17). PD-L1 is highly expressed in many malignant tumors $(18,19)$. Studies have shown that PD-L1 may be regulated by oncogenes and various signaling pathways (20-23). High expression of PD-L1 can reduce the immune effect of $\mathrm{T}$ cells in the local microenvironment of the tumor, thus facilitating tumor escape and promoting tumor growth $(24,25)$. LAG-3 is a super immunoglobulin IgG family member (26), which has a similar structure to CD4, and can combine with major histocompatibility complex (MHC) class II molecules. In the present study, it was observed that PD-L1 was highly expressed in colorectal cancer tissue, while LAG-3 was mainly expressed at the edge of tumor tissues. These results suggested that LAG-3 is expressed on tumor-infiltrating lymph node cells but not in colorectal cancer cells. Therefore, the immunoregulation of PD-L1 in colorectal cancer was investigated by blocking LAG-3 activity.

The PI3K/AKT signaling pathway is one of the most important cell survival pathways, and is closely associated with various malignant biological activities (27). Activation of PI3K can regulate the growth of tumor cells and prevent apoptosis (28) by activating a variety of downstream signals, including AKT, also known as PKB (protein kinase B), a serine/threonine kinase (13). AKT plays a key role in protein synthesis, cell metabolism, cell growth and proliferation, and angiogenesis $(29,30)$. It has previously been demonstrated that PI3K/AKT signaling pathway can affect cell apoptosis through a variety of mechanisms, including promoting P53 nucleus translocation $(28,31)$. In addition, PI3K/AKT can also modulate B cell lymphoma-2 associated agonist of cell death (Bad) activity, cause phosphorylation of caspase-9, block P53, and release apoptosis factors into the mitochondria (32). These mechanisms work together to block the process of programmed cell death, thus protecting the cells from apoptosis, promoting cell survival, and leading to the proliferation of tumor cells (33). The present study demonstrated that expression of $\mathrm{PI} 3 \mathrm{~K}$ and AKT in cancer tissues was significantly increased compared with paracancerous tissues, indicating that PI3K and AKT were activated in colorectal cancer tissues, and the expression levels of PI3K and AKT could reflect the growth and proliferation of tumor cells.

In the present study, a lentivirus encoding PD-L1 shRNA was used to transfect the CT26 cell line. PD-L1 expression significantly decreased following transfection in CT26 cells, which indicated the efficacy of the silencing, ensuring their suitable use in subsequent experiments. LAG-3 is expressed in a variety of immune types, and is mainly expressed on activated $\mathrm{T}$ cells and natural killer cells. LAG-3 has also been observed in activated $\mathrm{B}$ cells, $\mathrm{CD} 4^{+}$and $\mathrm{CD}^{+} \mathrm{T}$ cells activated by tumor tissue (34). LAG-3 plays an important immunomodulatory role in the occurrence and development of tumors, indicating that the growth of tumor cells is associated with an abnormal immune state (34). In the present study, the LAG-3 antibody was used to block the effect of LAG-3 on tumor growth. Thereafter, the effects of PD-L1 were compared in different groups. It was revealed that the weight of tumors was significantly decreased after blocking PD-L1, and tumor volume also decreased significantly; furthermore, the apoptosis of tumor cells increased, and the number and activity of $\mathrm{CD}^{+}$and $\mathrm{CD} 8^{+}$cells were also promoted after PD-L1 silencing. This may indicate that inhibition of PD-L1 affects the immune system and produces a large number of immune cells that destroy the tumor cells.

In order to demonstrate that the PI3K/AKT signaling pathway plays a regulatory role in tumor apoptosis, animal experiments were used to detect the effects of blocking PD-L1 on the PI3K/AKT signaling pathway. It was demonstrated that PD-L1 silencing inhibited PI3K and AKT expression in tumor cells. These results indicated that blocking PD-L1 enhanced 
the activity of $\mathrm{T}$ cells that destroy tumor cells, in a PI3K/AKT signaling-mediated manner, thereby inducing the apoptosis of tumor cells. Nevertheless, the potential oncogenes and tumor suppressor genes, such as P53, cyclin D1, and Bad should be investigated to confirm these effects. In addition, apoptosis-associated gene expression involved in both mitochondria-dependent and -independent signaling pathways still requires clarification.

In conclusion, blocking PD-L1 can inhibit tumor growth by activating $\mathrm{CD}^{+}$and $\mathrm{CD}^{+} \mathrm{T}$ cells, involved in the immune response. These data reveal critical immunomodulatory anticancer mechanisms.

\section{Acknowledgements}

Not applicable.

\section{Funding}

No funding was received.

\section{Availability of data and materials}

The datasets used during the present study are available from the corresponding author upon reasonable request.

\section{Authors' contributions}

YC, YH, XL and GW did the experiments and analyzed the data. YC and PC designed the study and wrote the manuscript. All authors read and approved the final manuscript.

\section{Ethics approval and consent to participate}

All experimental protocols were approved by the Ethics Committee of Fujian Medical University Union Hospital and written informed consent was obtained from all patients.

\section{Patient consent for publication}

Written informed consent was obtained.

\section{Competing interests}

The authors declare that they have no competing interests.

\section{References}

1. Gao Y, Wang J, Zhou Y, Sheng S, Qian SY and Huo X: Evaluation of serum CEA, CA19-9, CA72-4, CA125 and ferritin as diagnostic markers and factors of clinical parameters for colorectal cancer. Sci Rep 8: 2732, 2018.

2. Zhang M, Miao F, Huang R, Liu W, Zhao Y, Jiao T, Lu Y, Wu F, Wang X, Wang H, et al: RHBDD1 promotes colorectal cancer metastasis through the Wnt signaling pathway and its downstream target ZEB1. J Exp Clin Cancer Res 37: 22, 2018.

3. Mao X, Ou MT, Karuppagounder SS, Kam TI, Yin X, Xiong Y, Ge P, Umanah GE, Brahmachari S, Shin JH, et al: Pathological $\alpha$-synuclein transmission initiated by binding lymphocyteactivation gene 3. Science 353: aah3374, 2016.

4. Chen N, Liu Y, Guo Y, Chen Y, Liu X and Liu M: Lymphocyte activation gene 3 negatively regulates the function of intrahepatic hepatitis $\mathrm{C}$ virus-specific $\mathrm{CD}^{+} \mathrm{T}$ cells. J Gastroenterol Hepatol 30: 1788-1795, 2015.
5. Hald SM, Rakaee M, Martinez I, Richardsen E, Al-Saad S, Paulsen EE, Blix ES, Kilvaer T, Andersen S, Busund LT, et al: LAG-3 in non-small-cell lung cancer: Expression in primary tumors and metastatic lymph nodes is associated with improved survival. Clin Lung Cancer 19: 249-259, 2018.

6. Burugu S, Gao D, Leung S, Chia SK and Nielsen TO: LAG-3+ tumor infiltrating lymphocytes in breast cancer: Clinical correlates and association with PD-1/PD-L1+ tumors. Ann Oncol 28: 2977-2984, 2017.

7. Wang S, Liechty B, Patel S, Weber JS, Hollmann TJ, Snuderl M and Karajannis MA: Programmed death ligand 1 expression and tumor infiltrating lymphocytes in neurofibromatosis type 1 and 2 associated tumors. J Neurooncol 138: 183-190, 2018.

8. Gettinger SN, Horn L, Gandhi L, Spigel DR, Antonia SJ,Rizvi NA, Powderly JD, Heist RS, Carvajal RD, Jackman DM, et al: Overall survival and long-term safety of nivolumab (anti-programmed death 1 antibody, BMS-936558, ONO-4538) in patients with previously treated advanced non-small-cell lung cancer. J Clin Oncol 33: 2004-2012, 2015.

9. Carbognin L, Pilotto S, Milella M, Vaccaro V, Brunelli M Caliò A, Cuppone F, Sperduti I, Giannarelli D, Chilosi M, et al: Differential activity of nivolumab, pembrolizumab and MPDL3280A according to the tumor expression of programmed death-ligand-1 (PD-L1): Sensitivity analysis of trials in melanoma, lung and genitourinary cancers. PLoS One 10: e0130142, 2015.

10. Armand P, Shipp MA, Ribrag V, Michot JM, Zinzani PL, Kuruvilla J, Snyder ES, Ricart AD, Balakumaran A, Rose S, et al: Programmed death-1 blockade with pembrolizumab in patients with classical hodgkin lymphoma after brentuximab vedotin failure. J Clin Oncol 34: 3733-3739, 2016.

11. Robert C, Ribas A, Wolchok JD, Hodi FS, Hamid O, Kefford R, Weber JS, Joshua AM, Hwu WJ, Gangadhar TC, et al: Antiprogrammed-death-receptor-1 treatment with pembrolizumab in ipilimumab-refractory advanced melanoma: A randomised dose-comparison cohort of a phase 1 trial. Lancet 384: 1109-1117, 2014.

12. Taube JM, Klein A, Brahmer JR, Xu H, Pan X, Kim JH, Chen L, Pardoll DM, Topalian SL and Anders RA: Association of PD-1, PD-1 ligands, and other features of the tumor immune microenvironment with response to anti-PD-1 therapy. Clin Cancer Res 20: 5064-5074, 2014.

13. Zhu G, Wang X, Wu S, Li X and Li Q: Neuroprotective effects of puerarin on 1-methyl-4-phenyl-1,2,3,6-tetrahydropyridine induced Parkinson's disease model in mice. Phytother Res 28: 179-186, 2014.

14. Lambert E, Fuselier E, Ramont L, Brassart B, Dukic S, Oudart JB, Dupont-Deshorgue A, Sellier C, Machado C, Dauchez M, et al: Conformation-dependent binding of a Tetrastatin peptide to $\alpha_{\mathrm{v}} \beta_{3}$ integrin decreases melanoma progression through $\mathrm{FAK} / \mathrm{PI}{ }_{3} \mathrm{~K} / \mathrm{Akt}$ pathway inhibition. Sci Rep 8: 9837, 2018.

15. Tian J and Yuan L: Sirtuin 6 inhibits colon cancer progression by modulating PTEN/AKT signaling. Biomed Pharmacother 106: 109-116, 2018.

16. Li J, Chen H, Wu S, Cheng Y, Li Q, Wang J and Zhu G: MPP inhibits mGluR1/5-mediated long-term depression in mouse hippocampus by calpain activation. Eur J Pharmacol 795: 22-27, 2017.

17. Very N, Lefebvre $\mathrm{T}$ and El Yazidi-Belkoura I: Drug resistance related to aberrant glycosylation in colorectal cancer. Oncotarget 9: 1380-1402, 2017.

18. Santini FC and Hellmann MD: PD-1/PD-L1 axis in lung cancer. Cancer J 24: 15-19, 2018.

19. Mathew M, Enzler T, Shu CA and Rizvi NA: Combining chemotherapy with PD-1 blockade in NSCLC. Pharmacol Ther 186: 130-137, 2018.

20. Liu S, Chen S, Yuan W, Wang H, Chen K, Li D and Li D: PD-1/PD-L1 interaction up-regulates MDR1/P-gp expression in breast cancer cells via PI3K/AKT and MAPK/ERK pathways. Oncotarget 8: 99901-99912, 2017.

21. Almozyan S, Colak D, Mansour F, Alaiya A, Al-Harazi O, Qattan A, Al-Mohanna F, Al-Alwan M and Ghebeh H: PD-L1 promotes OCT4 and Nanog expression in breast cancer stem cells by sustaining PI3K/AKT pathway activation. Int J Cancer 141: 1402-1412, 2017.

22. Lopez-Rivera E, Jayaraman P, Parikh F, Davies MA, Ekmekcioglu S, Izadmehr S, Milton DR, Chipuk JE, Grimm EA, Estrada Y, et al: Inducible nitric oxide synthase drives mTOR pathway activation and proliferation of human melanoma by reversible nitrosylation of TSC2. Cancer Res 74: 1067-1078, 2014. 
23. Zhang X, Zeng Y, Qu Q, Zhu J, Liu Z, Ning W, Zeng H, Zhang N, Du W, Chen C, et al: PD-L1 induced by IFN- $\gamma$ from tumor-associated macrophages via the JAK/STAT3 and PI3K/AKT signaling pathways promoted progression of lung cancer. Int $\mathbf{J}$ Clin Oncol 22: 1026-1033, 2017.

24. Blank C, Brown I, Peterson AC, Spiotto M, Iwai Y, Honjo T and Gajewski TF: PD-L1/B7H-1 inhibits the effector phase of tumor rejection by $\mathrm{T}$ cell receptor $(\mathrm{TCR})$ transgenic $\mathrm{CD} 8^{+} \mathrm{T}$ cells Cancer Res 64: 1140-1145, 2004.

25. Francisco LM, Salinas VH, Brown KE, Vanguri VK, Freeman GJ, Kuchroo VK and Sharpe AH: PD-L1 regulates the development, maintenance, and function of induced regulatory $\mathrm{T}$ cells. J Exp Med 206: 3015-3029, 2009.

26. Nguyen LT and Ohashi PS: Clinical blockade of PD1 and LAG3-potential mechanisms of action. Nat Rev Immunol 15: 45-56, 2015.

27. Thorpe LM, Yuzugullu H and Zhao JJ: PI3K in cancer: Divergent roles of isoforms, modes of activation and therapeutic targeting. Nat Rev Cancer 15: 7-24, 2015.

28. Zhu G, Wang X, Wu S and Li Q: Involvement of activation of $\mathrm{PI} 3 \mathrm{~K} / \mathrm{Akt}$ pathway in the protective effects of puerarin against $\mathrm{MPP}^{+}$-induced human neuroblastoma SH-SY5Y cell death. Neurochem Int 60: 400-408, 2012.

29. Maugeri G, D'Amico AG, Rasà DM, Saccone $S$, Federico $C$, Magro G, Cavallaro S and D'Agata V: Caffeine inhibits angiogenesis in human glioblastoma cells via HIFs modulation. Anticancer Agents Med Chem: Feb 9, 2018 (Epub ahead of print). doi: 10.2174/1871520618666180209151750.
30. Li J, Yang S and Zhu G: Postnatal calpain inhibition elicits cerebellar cell death and motor dysfunction. Oncotarget 8: 87997-88007, 2017.

31. Suh DS, Park SE, Jin H, Lee K and Bae J: LRIG2 is a growth suppressor of Hec-1 A and Ishikawa endometrial adenocarcinoma cells by regulating PI3K/AKT- and EGFR-mediated apoptosis and cell-cycle. Oncogenesis 7: 3, 2018.

32. Chen L, Xiong YQ, Xu J, Wang JP, Meng ZL and Hong YQ: Juglanin inhibits lung cancer by regulation of apoptosis, ROS and autophagy induction. Oncotarget 8: 93878-93898, 2017.

33. Okamura T, Fujio K, Shibuya M, Sumitomo S, Shoda H, Sakaguchi S and Yamamoto K: CD4 ${ }^{+} \mathrm{CD} 25^{-} \mathrm{LAG}^{+}$regulatory T cells controlled by the transcription factor Egr-2. Proc Natl Acad Sci USA 106: 13974-13979, 2009.

34. Okamura T, Sumitomo S, Morita K, Iwasaki Y, Inoue M, Nakachi S, Komai T, Shoda H, Miyazaki J, Fujio K and Yamamoto K: TGF- $\beta 3$-expressing $\mathrm{CD} 4^{+} \mathrm{CD} 25 \mathrm{LAG}^{+}$regulatory $\mathrm{T}$ cells control humoral immune responses. Nat Commun 6: 6329, 2015.

This work is licensed under a Creative Commons Attribution-NonCommercial-NoDerivatives 4.0 International (CC BY-NC-ND 4.0) License. 